\title{
ВЛИЯНИЕ СПОСОБА СШИВКИ И РЕЦЕПТУРЫ ПЕНОПОЛИЭТИЛЕНА НА ЕГО ЭЛЕКТРЕТНЫЕ СВОЙСТВА
}

\author{
И. Р. Гильманов, М.Ф. Галиханов, А.Р. Гильманова
}

\begin{abstract}
ИСКАНДЕР РАНАСОВИЧ ГИЛЬМАНОВ - аспирант кафедры технологии переработки полимеров и композиционных материалов казанского национального исследовательского технологического университета.E-mail: gilmanov_iskander@mail.ru.
\end{abstract}

МАНСУР ФЛОРИДОВИЧ ГАЛИХАНОВ - доктор технических наук, профессор кафедры технологии переработки полимеров и композиционных материалов казанского национального исследовательского технологического университета.E-mail: mgalikhanov@yandex.ru.

\begin{abstract}
АЛЬФИНА РАНАСОВНА ГИЛЬМАНОВА - сотрудник кафедры технологии переработки полимеров и композиционных материалов казанского национального исследовательского технологического университета.E-mail: alfina-gilmanova@mail.ru.
\end{abstract}

420015, Казань, Российская Федераџия, ул. Карла Маркса, 68. Кафедра технологии переработки полимеров и композиционных материалов, Казанский национальный исследовательский технологический университет.

В работе изучены электретные (в том числе и пьезоэлектрические) свойства пенополиэтилена различных марок, а также влияние на них наполнителя. Исследования показали, что лучшими электретными характеристиками обладает химически сшитый пенополиэтилен, наполненный техническим углеродом. Это обусловлено меньшей подвижностью макромолекул полимера, наличием гранищы раздела фаз «полимер - наполнитель», на которой сосредоточены энергетически глубокие ловушки носителей заряда, и оптимальными структурными характеристиками исследуемых газонаполненных полимеров. Пьезоэлектрический коэффичиент пенополиэтилена тем больще, чем выше значения его потенцила поверхности, эффективной поверхностной плотности заряда и напряженности электрического поля.

Ключевые слова: пенополиэтилен, электретные свойства, пьезоэлектрический коэффициент, сшивка, наполнитель.

\section{INFLUENCE OF THE CROSSLINKING METHOD AND THE FORMULATION OF POLYETHYLENE FOAM ON ITS ELECTRET PROPERTIES}

\author{
I. R. Gilmanov, M. F. Galikhanov, A. R. Gilmanova \\ Department of Processing and Certification of Plastics and Composite Materials, Kazan National Research \\ Technological University, 68 Karl Marx St., 420015 Kazan, Russia.
}

In this work, we studied the electret (including piezoelectric) properties of polyethylene foam of various brands, as well as the effect of the filler on them. Studies have shown that chemically cross-linked polyethylene foam filled with carbon black has the best electret characteristics. This is explained to several factors: the lower 
mobility of the polymer macromolecules, the presence of a polymer-filler interface, on which energetically deep traps of charge carriers are concentrated, and the optimal structural characteristics of the gas-filled polymers under study. Thus, the higher the values of the surface potential, the effective surface charge density and the electric field strength, the higher the piezoelectric coefficient of the samples of polyethylene foam of various brands.

Key words: polyethylene foam, electret properties, piezoelectric coefficient, crosslinking, filler.

\section{Введение}

Электреты представляют особый класс диэлектрических материалов, являющихся источником постоянного электрического поля. Они применяются в различных областях - в электронике, в медицине, в биотехнологии, при фильтрации, упаковке и т.д. [1, 2].

В последнее время наблюдается тенденция создания электретов на основе газонаполненных полимерных материалов [3-6]. Одним из наиболее распространенных полимеров для получения газонаполненных композиций является полиэтилен, что связано с его доступностью и дешевизной $[5,7]$.

Производство пенополиэтилена может проходить по одной из следующих технологий. Получение несшитого пенополиэтилена проходит без химической реакции, когда сохраняется изначальная молекулярная структура полимера, и протекает в несколько этапов: плавление гранулированного сырья; подача газа (фреона или изобутана) в материальный цилиндр с равномерно перемешиваемым расплавом полимера. Сразу на выходе из формующей головки экструдера происходит процесс вспенивания, после чего полученный материал охлаждается. Химически сшитый пенополиэтилен получают при участии сшивающих (перекись дикумила) и вспенивающих (азодикарбонамид) агентов. Совмещение процессов сшивания и вспенивания в одном технологическом цикле является относительным новшеством. Азодикарбонамид одновременно является и вспенивающим веществом, и зародышеобразователем. Производство физически сшитого вспененного полиэтилена (ФППЭ) зачастую проходит при участии вспенивающего реактива и радиации [8].

Для получения материалов с новым или улучшенным комплексом свойств, применяют смешение полимером с различными добавками (наполнителями, пластификаторами и т.п.). Одним из часто используемых наполнителей является технический углерод (сажа). Его введение способно замедлить «старение» полимера, затормозить окислительную деструкцию его макромолекул, упрочнить материал, придать электропроводные и антистатические свойства и т.д. Другой наполнитель, оксид цинка, известный также как цинковые белила, обладает хорошей светостойкостью и обеспечивает защиту от ультрафиолетового излучения. Помимо этого, окись цинка используется в качестве пигмента и наполнителя при производстве пластмасс, резины, бумаги.

Также существуют работы исследователей, в которых изучается влияние различных наполнителей электретные (в том числе и пьезоэлектрические) свойства полимеров [9-12].

Исходя из вышесказанного, целью данной работы явилось исследование влияния технологии получения электретного пенополиэтилена и применения наполнителя на уровень его электретных и пьезоэлектрических свойств.

\section{Методика эксперимента}

В качестве объектов исследования были выбраны листы несшитого пенополиэтилена (НППЭ) марки НППЭ 10 , химически сшитого пенополиэтилена (ХППЭ) марок ХППЭ 3010-Н и ХППЭ 3010-А (с сажей), а также физически сшитого пенополиэтилена (ФППЭ) марки ФППЭ 3010-H с ZnO и без наполнителя, изготовленные на основе полиэтилена (ПЭ) марки 15803-020. Толщина листов составляла 10 мм. Состав полимерных композиций приведен в таблице 1.

Электретирование образцов производили в отрицательном коронном разряде при напряжении, подаваемом на коронирующий электрод, 30 кВ, время воздействия составляло 30 с. Предварительно образцы нагревали до $90{ }^{\circ} \mathrm{C}$ в термошкафу в течение 10-15 мин.

С помощью измерителя параметров электростатического поля ИПЭП-1 (методом периодического экранирования приёмного электрода), находящегося на расстоянии 2 см от поверхности электрета, проводили измерение потенциала поверхности $V_{\text {э }}$ эффективной поверхностной плотности зарядов $\sigma_{э ф}$ и напряжённости электрического поля $E$ образцов.

Исследование влияния статических нагрузок на электретные свойства пенополиэтилена различных марок проводилось следующим образом. Сначала измерялись электретные характеристики образцов до нагрузки, затем производилось создание 
Рецептура пенополиэтилена различных марок

\begin{tabular}{lccccc}
\hline $\begin{array}{c}\text { Компоненты состава, } \\
\text { \% }\end{array}$ & $\begin{array}{c}\text { ХППЭ } \\
\mathbf{3 0 1 0 - H}\end{array}$ & $\begin{array}{c}\text { ХППЭ } \\
\mathbf{3 0 1 0 - \mathbf { A }}\end{array}$ & $\begin{array}{c}\text { ФППЭ } \\
\mathbf{3 0 1 0}-\mathbf{H}\end{array}$ & $\begin{array}{c}\text { ФППЭ } \\
\mathbf{3 0 1 0}-\mathbf{H}\end{array}$ & $\begin{array}{c}\text { НППЭ } \\
\mathbf{1 0}\end{array}$ \\
\hline Полиэтилен & 86,5 & 84,5 & 87 & 84,5 & 100 \\
Азодикарбонамид & 13 & 13 & 13 & 13,5 & - \\
Перекись дикумила & 0,5 & 0,5 & - & - & - \\
$\begin{array}{l}\text { Мелкодисперсный } \\
\text { наполнитель }\end{array}$ & - & 2 (сажа) & - & $2(\mathrm{ZnO})$ & - \\
\hline
\end{tabular}

статической нагрузки сжатия, и проводилось измерение электретных характеристик после сжатия. Для создания статической нагрузки образцы помещали под груз весом 7 кг и выдерживали в течение 1 часа.

Измерение пьезокоэффициента $d_{33}$ осуществляли на электрометре Keithley. Предварительно производилось электретирование образцов при напряжении 25 кВ, подаваемом на коронирующий электрод, в течение 60 с и без нагрева образцов.

Определение степени сшивки проводили согласно стандарту ISO 10147-2011. В качестве растворителя применяли ксилол, время экстракции 8 часов.

Изучение структуры исследуемых образцов проводили с помощью оптического микроскопа Bresser Junior 40-1024×.

\section{Результаты и обсуждение}

Короноэлектреты, которые характеризуются наличием гомозаряда, как правило, изготавливают воздействием поля постоянного коронного разряда на диэлектрик. При заряжении, на один из электродов, выполненный в виде набора игл, подаётся высокое напряжение, при этом возникает ионизированный воздух-плазма, а сам диэлектрик должен находиться в контакте с заземлённым металлическим электродом. В этом случае ионы либо переносят свой заряд на диэлектрик и возвращаются обратно в воздух, либо проникают в приповерхностную область диэлектрика, где они фиксируются ионными ловушками.

На начальном этапе данной работы были изучены образцы несшитого пенополиэтилена и химически сшитого пенополиэтилена, затем было проведено сравнение этих образцов с ХППЭ с сажей. На рисунке 1 представлена зависимость потенциала поверхности исследуемых материалов от времени хранения - кривая релаксации заряда во времени. Начальный, более крутой участок кривой обусловлен высвобождением носителей заряда из энергетически мелких ловушек. Второй, более пологий участок кривой - период, когда

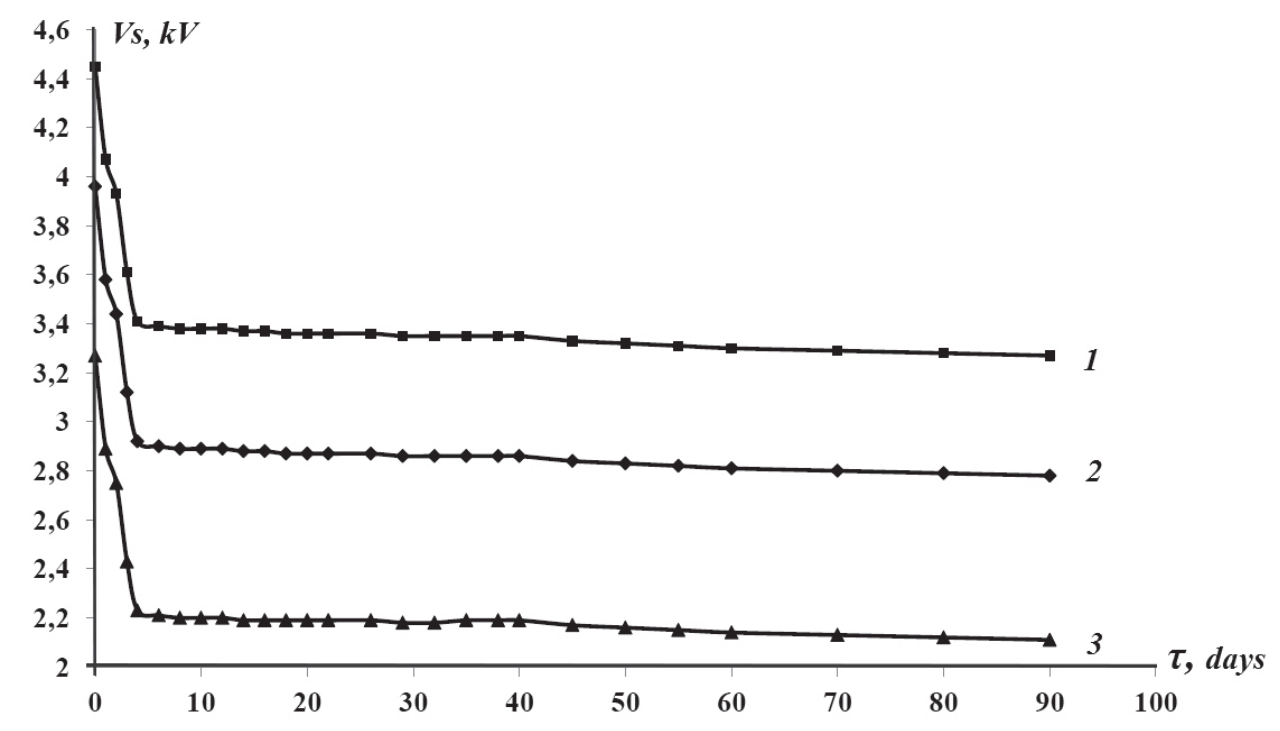

Рис. 1. Зависимость потенциала поверхности зарядов от времени хранения для образцов НППЭ 10 (3) и ХППЭ 3010-Н (2) и ХППЭ 3010-А (1) 


\section{Таблииа 2}

Электретные характеристики пенополиэтилена различных марок на 90 сутки хранения

\begin{tabular}{|c|c|c|c|}
\hline \multirow{2}{*}{ Образец } & \multicolumn{3}{|c|}{$\begin{array}{c}\text { Электретные свойства } \\
\text { на } 90 \text { сутки хранения }\end{array}$} \\
\hline & $\begin{array}{l}\mathbf{V}_{,}, \\
\mathbf{K B}\end{array}$ & $\begin{array}{c}E, \\
\kappa B / M\end{array}$ & $\underset{\text { мККл/M }}{\sigma_{\text {ээ }},}$ \\
\hline НППЭ 10 & 1,44 & 97,8 & 0,87 \\
\hline ХППЭ 3010-Н & 2,12 & 129,7 & 1,13 \\
\hline $\begin{array}{l}\text { ХППЭ 3010-А } \\
\text { (с сажей) }\end{array}$ & 2,61 & 159,5 & 1,42 \\
\hline ФППЭ 3010-Н & 2,28 & 138,8 & 1,24 \\
\hline $\begin{array}{l}\text { ФППЭ 3010-Н } \\
\text { c ZnO }\end{array}$ & 1,77 & 106,9 & 0,96 \\
\hline
\end{tabular}

происходит стабилизация электретных свойств, величина которых определяется наличием носителей заряда в глубоких энергетических ловушках диэлектрика.

Значения эффективной поверхностной плотности зарядов, потенциала поверхности и напряжённости электрического поля пенополиэтилена на 90 сутки хранения представлены в таблице 2 .

Видно, что лучшими электретными свойствами обладает ХППЭ, содержащий технический углерод. Это может быть обусловлено несколькими причинами.

Во-первых, повышенные значения электретных свойств ХППЭ может быть связано с уменьшением подвижности макромолекул полиэтилена при химической сшивке и при добавлении дисперсного наполнителя. Уменьшение подвижности макромолекул полимера ведет к затормаживанию релаксационных процессов, что повышает стабильность электретного состояния в нем. Об этом свидетельствует и большая степень сшивки ХППЭ $(84,3 \%)$ по сравнению с ФППЭ (63,0 \%)
Во-вторых, ХППЭ с сажей обладает большой площадью поверхности «полимер - наполнитель». Известно, что частицы технического углерода представляют собой глобулы, состоящие из деградированных графитовых структур. Поверхность частиц обладает шероховатостью за счёт наползающих друг на друга слоёв. Частицы в процессе получения объединяются в агрегаты, которые слипаются в менее прочные образования - в «хлопья». Благодаря этому технический углерод обладает высокоразвитой поверхностью. Это приводит к увеличению количества носителей зарядов, закрепленных в глубоких ловушках, что обуславливает повышение электретных свойств пенополиэтилена. Помимо этого, на поверхности частиц сажи обнаруживаются группы $-\mathrm{COOH},-\mathrm{CHO}$, $-\mathrm{OH},-\mathrm{COO},-\mathrm{CO}$ и сорбированные остатки неразложившихся углеводородов, которые являются дополнительными ловушками носителей заряда.

Также одной из мелкодисперсных добавок в составе физически сшитого пенополиэтилена используется оксид цинка, но его добавление несколько ухудшило электретные характеристики материала. Это может быть связано с увеличением электропроводности композиции.

В-третьих, химически сшитый полиэтилен может обладать оптимальными структурными характеристиками среди всех исследуемых газонаполненных полимеров. Оптическая микроскопия показала (рис. 2), что средний размер газовык ячеек НППЭ составляет 1,6 мм, ФППЭ - 0,67 мм, а ХППЭ $-0,84$ мм. Это означает, что различия в их структуре не являются основной причиной повышенных электретных свойств ХППЭ.

Так как многие сферы применения вспененных полимеров предусматривают их деформационное воздействие, следующим этапом исследования было изучение зависимости электретных характеристик пенополиэтилена до и после приложения периодических нагрузок (рис. 3,4 ).

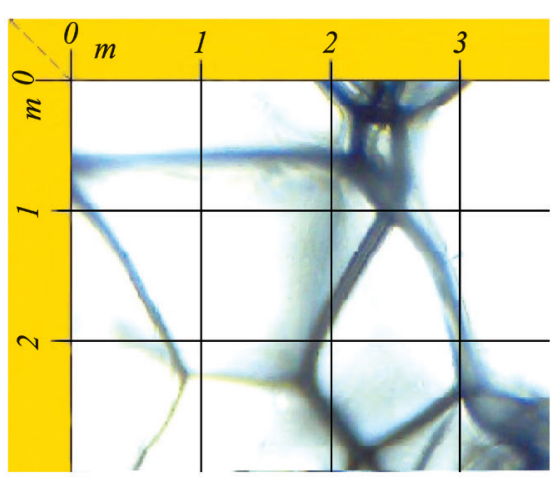

1

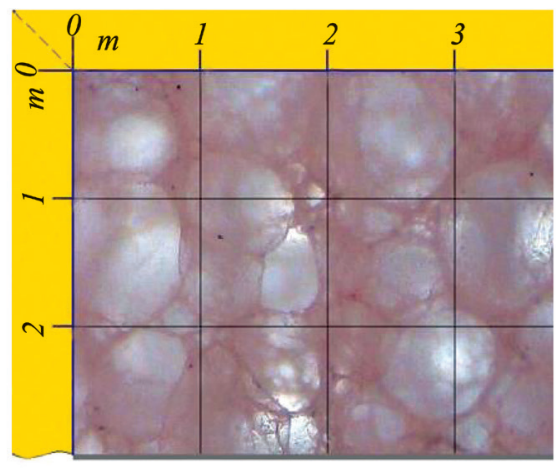

2

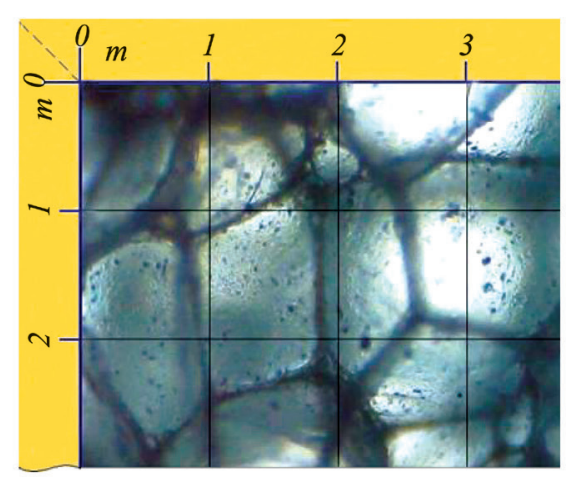

3

Рис. 2. Структурные параметры НППЭ (1) ФППЭ (2) и ХППЭ (3) под микроскопом 


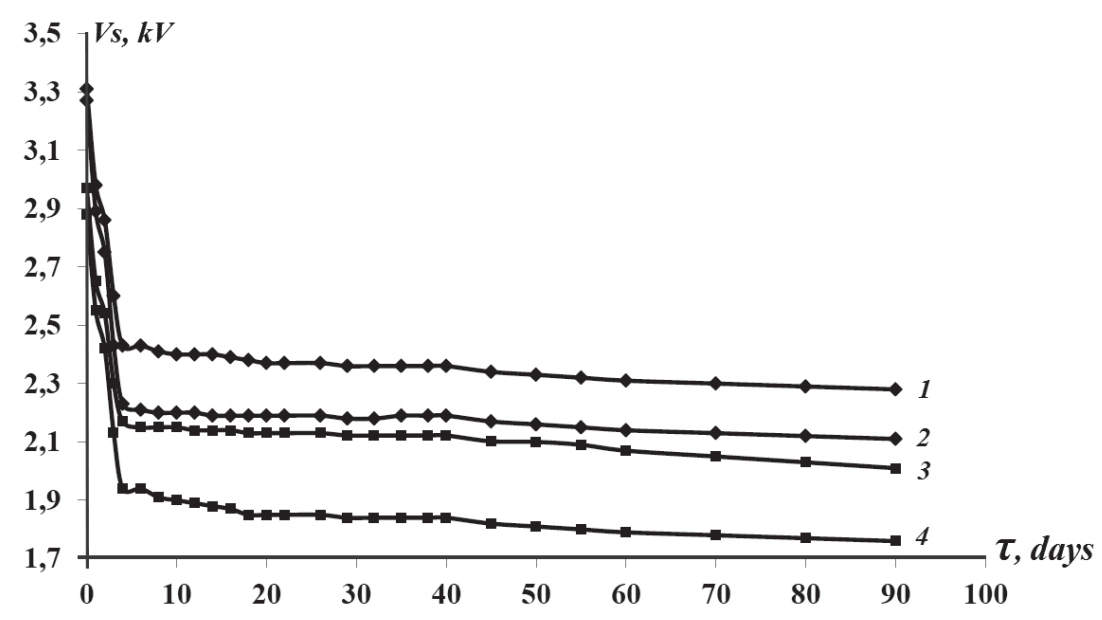

Рис. 3. Зависимость потенциала поверхности от времени хранения для ФППЭ 3010-Н и НППЭ 10 до $(1,2)$ и после $(3,4)$ приложения нагрузки

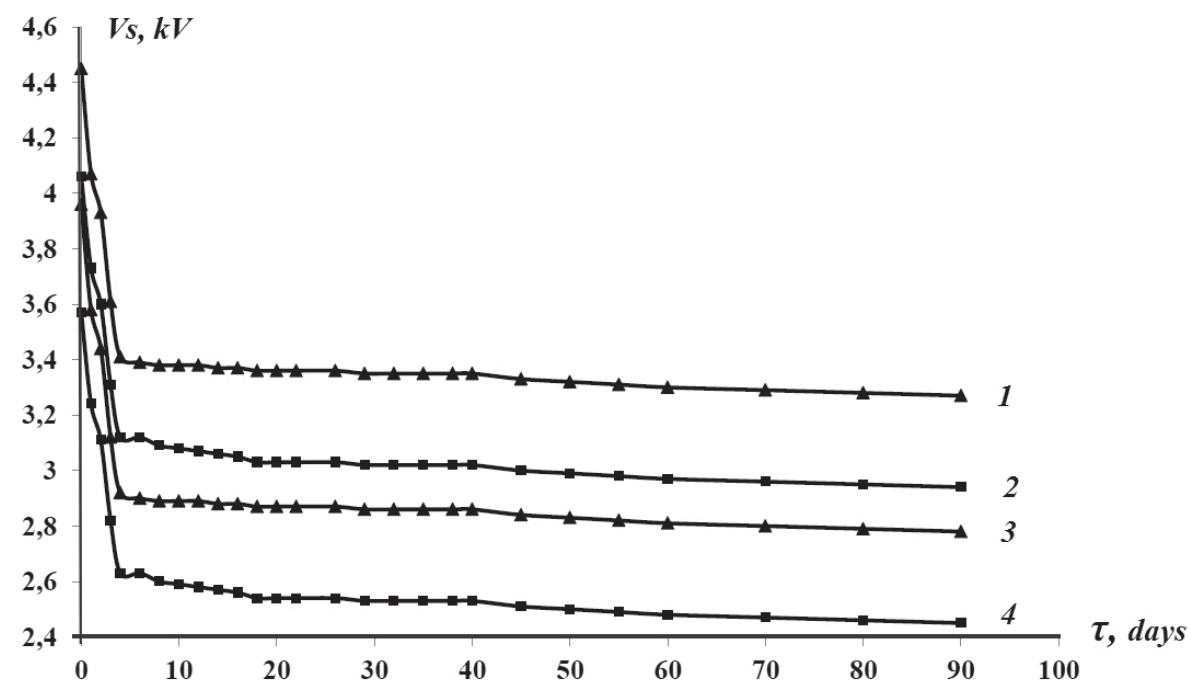

Рис. 4. Зависимость потенциала поверхности от времени хранения для образцов ХППЭ 3010-А и ХППЭ 3010-Н до $(1,3)$ и после $(2,4)$ приложения нагрузки

Из рисунков 3, 4 видно, что при приложении нагрузки снижается значение потенциала поверхности пенополиэтилена, что можно объяснить сближением диполей и носителей заряда в энергетических ловушках, вследствие чего частично происходит взаимная компенсация гомо- и гетерозаряда. После снятия нагрузки образцы принимают прежний объем, диполи и заряды в ловушках возвращаются в исходное положение, при этом восстанавливаются значения электретных характеристик материалов.

Пьезокоэффициенты пенополиэтилена различных марок представлены в таблице 3 .

Измерение пьезоэлектрического коэффициента образцов вспененного полиэтилена различных марок показало, что химически сшитый пенопо-
Таблица 3

Пьезокоэффициент образцов вспененного полиэтилена различных марок

\begin{tabular}{lc}
\hline \multicolumn{1}{c}{ Образец } & $\begin{array}{c}\text { Пьезокоэффициент, } \\
\text { пКл/н }\end{array}$ \\
\hline НППЭ 10 & 80 \\
ХППЭ 3010-Н & 185 \\
ХППЭ 3010-А & 383 \\
ФППЭ 3010-Н & 80 \\
ФППЭ 3010-H с ZnO & 90 \\
\hline
\end{tabular}

лиэтилен имеет пьезокоэффициент в 2 раза больше по сравнению с несшитым пенополиэтиленом 383 пКл/Н и 185 пКл/Н соответственно. Понижен- 
ные значения пьезомодуля НППЭ можно объяснить тем, что для этих образцов требуется больше времени для восстановления прежнего объема после релаксации благодаря несшитой структуры. Введение в состав ХППЭ технического углерода приводит к снижению пьезокоэффициента до 80 пКл/Н. Пьезокоэффициенты образцов ФППЭ и ФППЭ с ZnO также низки - 80 и 90 пКл/Н, соответственно.

Полученные данные свидетельствуют о том, что значения пьезокоэффициентов образцов увеличиваются параллельно с увеличением других электретных свойств (эффективной поверхностной плотности зарядов, потенциала поверхности и напряжённости электрического поля).

\section{Выводы}

Лучшими электретными характеристиками обладает образец вспененного полиэтилена, представляющий ХППЭ, содержащий технический углерод, улучшенные электретные свойства которого обусловлены наличием границы фаз раздела «полимер - наполнитель». Это приводит к увеличению количества глубоких ловушек носителей зарядов, как следствие, к увеличению количества инжектированных носителей заряда в эти ловушки. Все это и объясняет повышенные значения электретных характеристик ХППЭ с содержанием сажи по сравнению с другими марками пенополиэтилена.

Значения пьезоэлектрического коэффициента образцов пенополиэтилена находятся в прямой зависимости от величины их потенциала поверхности, эффективной поверхностной плотности за- рядов и напряжённости электрического поля. Чем выше эти значения, тем выше значение пьезокоэффициента пенополиэтилена.

\section{Литература}

1. Сесслер Г. Электреты / Г. Сесслер; под ред. Сесслера Г. М.: Мир. 1983. 487 c.

2. Пинчук Л.С. Электретные материалы в машиностроении / Л.С. Пинчук, В.А. Гольдаде. - Гомель: Инфотрибо, 1998. -288 с.

3. Xia Z. J. Phys. D: Appl. Phys. 1999. V. 32. P. L83-L85.

4. Gilmanov I.R. AIP Conference Proceedings. 2017. V. 1886. 020079.

5. Halina Kaczmarek. Journal of Materials Science Materials in Electroni. 2017. V. 28. P. 1526.

6. Зайцева М.Ю. Вестник Казанского технологического университета. 2010. №9. С. 210-213.

7. Остапчук Д.Е. Использование вспененных полимерных материалов-полиэтилена и полипропилена в качестве нефтесорбентов / Остапчук Д.Е, Домрачева В.А., Трусова В.В. // Материалы докладов XXIII Всероссийской студенческой научно-практической конференции с международным участием «Проблемы экологической и промышленной безопасности современного мира». 2018. С. 168-170.

8. Gilmanov I.R. AIP Conference Proceedings. 2017. V. 1886. P. 020079.

9. Галиханов М.Ф. Пластические массы. 2002. № 10. C. 61-67.

10. Галиханов М.Ф. Известия высших учебных заведений. Серия: Химия и химическая технология. 2005. T. 48. №5. C. 89.

11. Halina Kaczmarek. Pure and Applied Chemistry. 2019. V. 91. P. 967-982.

12. Khusniddinovich M.B. International Journal of Scientific and Technology Research. 2019. V. 8. P. 1068-1070. 